\title{
N-Heterocyclic Carbene-Stabilized Homoatomic Lithium(0) Complexes with a Lithium- Lithium Covalent Bond: A Theoretical Design and Characterization
}

Caixia Yuan, ${ }^{\dagger, \dagger}$ Yan-Bo Wu, ${ }^{\dagger, \dagger}$ and Xiaotai Wang ${ }^{*}, \dagger$

'Department of Chemistry, University of Colorado Denver, Campus Box 194, P.O. Box

173364, Denver, Colorado 80217-3364, United States

Institute of Molecular Science, Shanxi University, Taiyuan, Shanxi 030006, People’s

Republic of China

Corresponding Author: xiaotai.wang@ucdenver.edu

\begin{abstract}
Density functional theory calculations (B3LYP and B2PLYP-D2) have been utilized to design and characterize novel homoatomic lithium(0) organometallic complexes of the $\mathrm{NHC} \rightarrow \mathrm{Li}-\mathrm{Li} \leftarrow \mathrm{NHC}$ type (NHC $=$ N-heterocyclic carbenes). The computed $\mathrm{Li}-\mathrm{Li}$ bond length and energy are consistent with those experimentally observed for $\operatorname{Li}_{2}(\mathrm{~g})$. These and other structural and energetic data suggest that such organolithium compounds should be viable targets for synthesis. These compounds would represent a new class of molecular "allotropes" and could have novel reactivities.
\end{abstract}

A significant recent development in main-group organometallic chemistry has been the utilization of strong $\sigma$-donor ligands, typically N-heterocyclic carbenes (NHC), in stabilizing low-valent and zerovalent main-group complexes containing homoatomic element-element bonds. ${ }^{1}$ The zerovalent complexes have been described as molecular "allotropes" of elements. The study of these low-valent and zerovalent NHC complexes also dovetails with the field of main-group multiple bonding chemistry, ${ }^{2}$ thereby leading to the extraordinary synthesis of molecules with boron-boron double and triple bonds, as shown in Figure 1. ${ }^{3,4}$ It should be

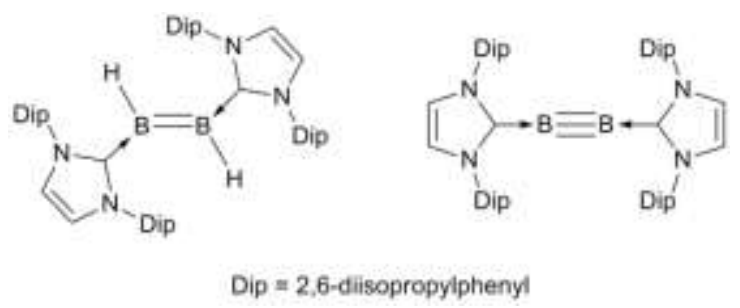

Figure 1. NHC-stabilized complexes containing $\mathrm{B}=\mathrm{B}$ and $\mathrm{B} \equiv \mathrm{B}$ bonds.

noted that computational studies and predictions of relevant boron systems contributed to these experimental achievements. ${ }^{5-9}$ A recent computational study suggests that beryllium $(0)$ complexes of the $\mathrm{NHC} \rightarrow \mathrm{Be}=\mathrm{Be} \leftarrow \mathrm{NHC}$ type could also occur as stable molecules. ${ }^{10}$ Could this chemistry be extended to the Group 1 element lithium, with an aim at homoatomic lithium( 0 ) complexes of the $\mathrm{NHC} \rightarrow \mathrm{Li}-\mathrm{Li} \leftarrow \mathrm{NHC}$ type with a $2 \mathrm{c}-2 \mathrm{e}$ lithium-lithium covalent 
bond? It is well known that lithium has a greater tendency to exhibit covalent bonding than any other Group 1 metal. ${ }^{11}$ To our knowledge, lithium(0) complexes have not been known experimentally or theoretically. Dilithium $\left(\mathrm{Li}_{2}\right)$, a molecule with two lithium(0) atoms, has been observed in the gas phase with a $\mathrm{Li}-\mathrm{Li}$ bond distance of $2.673 \AA^{12}$ and a bond energy in the range of $22.7-26.4 \mathrm{kcal} / \mathrm{mol} .{ }^{13-17}$ A number of lithium(I) complexes with NHC ligands have been synthesized and characterized, in which the lithium(I) centers coordinate to the NHC carbenic carbon atoms. ${ }^{18-24}$

In this Communication, we report a computational study on $\mathrm{NHC} \rightarrow \mathrm{Li}-\mathrm{Li} \leftarrow \mathrm{NHC}$ complexes at the B3LYP and the higher B2PLYP-D2 levels of density functional theory (DFT), ${ }^{25,26}$ B3LYP being the common hybrid functional ${ }^{27}$ and B2PLYP-D2 being a dispersion-corrected double hybrid functional that combines exact Hartree-Fock exchange with an MP2-like correlation. ${ }^{28}$

A general method for attaining low-coordinate complexes is to employ bulky ligands, and as such, the synthesis of $\mathrm{NHC} \rightarrow \mathrm{Li}-\mathrm{Li} \leftarrow \mathrm{NHC}$ would require a large $\mathrm{NHC}$ to effect the low coordination number (two) for lithium and to protect the dilithium core. Thus, we used the bulky IDip (1,3-bis(2,6-diisopropylphenyl)imidazol-2-ylidene) ligand set to simulate the experimental situation, and studied the geometries of IDipLiLiIDip at the B3LYP/6-31+G(d) level of theory. We successfully located two conformational isomers of IDipLiLiIDip (1a and 1b) as energy minima (Figure 2). The DFT wavefunctions of $\mathbf{1 a}$ and $\mathbf{1 b}$ both were checked to be stable. Thermodynamically, $\mathbf{1 a}$ is more stable than $\mathbf{1 b}$ by $0.5 \mathrm{kcal} / \mathrm{mol}$ in Gibbs free energy.
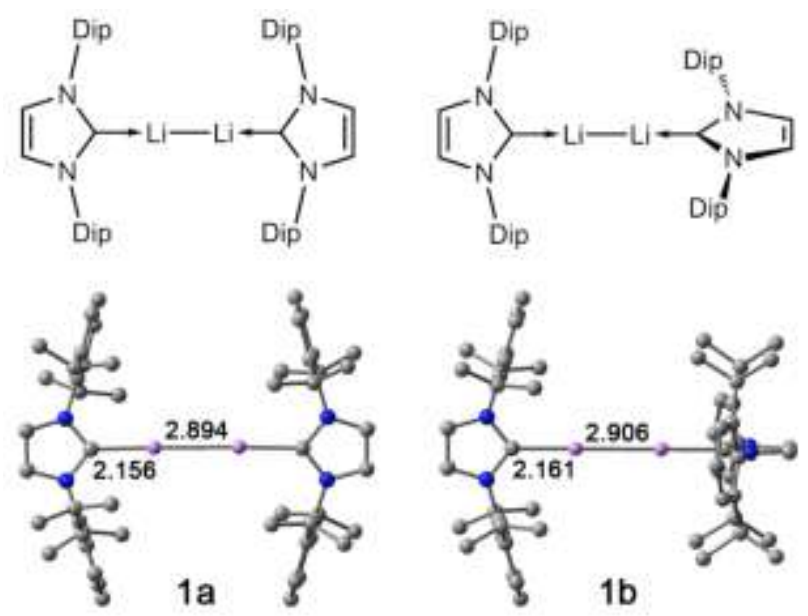

Figure 2. Geometries of the rotamers $\mathbf{1 a}$ and $\mathbf{1 b}$ of IDipLiLiIDip optimized with B3LYP/6$31+G(d)$. Hydrogen atoms are omitted for clarity. Selected bond distances are given in units of $\AA$. 
Both $\mathbf{1 a}$ and $\mathbf{1 b}$ exhibit an essentially linear arrangement of the $\mathrm{C}-\mathrm{Li}-\mathrm{Li}-\mathrm{C}$ axis. The two NHC rings in 1a are slightly deviated from coplanar (dihedral angle $=8.4^{\circ}$ ), and those in 1b are perpendicular to each other. The $\mathrm{Li}-\mathrm{C}$ bond distances are 2.156 and $2.161 \AA$ in $\mathbf{1 a}$ and $\mathbf{1 b}$, respectively, which are consistent with the sum of the covalent radii of lithium and carbon $(2.07 \AA) .{ }^{29,30}$ More importantly, the Li-C bond distances are similar to the experimentally determined bond lengths $(2.056-2.169 \AA)$ for the $\mathrm{Li}-\mathrm{C}$ bonds to the terminal carbenic carbon atoms in several $\mathrm{Li}(\mathrm{I})-\mathrm{NHC}$ complexes that have been crystallographically characterized. ${ }^{18,19,21-24}$ This comparison gives convincing support for the $\mathrm{Li}-\mathrm{C}$ coordinate covalent bonds in $\mathbf{1 a}$ and $\mathbf{1 b}$. The $\mathrm{Li}-\mathrm{Li}$ bond distances are 2.894 and $2.906 \AA$ in $\mathbf{1 a}$ and $\mathbf{1 b}$, respectively, which are slightly longer than that in $\mathrm{Li}_{2}(2.673 \AA) .{ }^{12}$ This is understandable by considering that each lithium atom in $\mathbf{1 a}$ and $\mathbf{1 b}$ is two-coordinate as opposed to the monobonded lithium atoms in $\mathrm{Li}_{2}$. Nevertheless, the $\mathrm{Li}-\mathrm{Li}$ bond distances in $\mathbf{1 a}$ and $\mathbf{1 b}$ are shorter than the closest $\mathrm{Li}-\mathrm{Li}$ bond distance in the metallic crystal of lithium $(3.04 \AA),{ }^{31}$ and are much less than two times the Van der Waals radius of lithium $(3.64 \AA) .{ }^{32}$ Thus, a Li-Li covalent bond occurs in $\mathbf{1 a}$ and $\mathbf{1 b}$, which is corroborated by the calculated Wiberg bond indices for the lithium-lithium bonds ( 0.89 in $\mathbf{1 a}$ and 0.90 in $\mathbf{1 b}$ ).

To further characterize and validate NHCLiLiNHC complexes, we used 1,3dimethylimidazol-2-ylidene (IMe), namely the methyl-substituted NHC, as a model to compute the structures and energetics of IMeLiLiIMe at higher levels of theory. We studied the geometries of IMeLiLiIMe using both B3LYP and B2PLYP-D2 combined with the more complete basis set 6-311++G(d,p). The two methods gave consistent geometric and energetic results, as shown in Table 1.

Table 1. Geometry and energy data for IMeLiLiIMe ${ }^{a}$

\begin{tabular}{|c|c|c|c|c|}
\hline & $\mathrm{Me}$ & $\mathrm{Me}^{\mathrm{N}}$ & $\mathrm{Me}^{\mathrm{N}}$ & b Mé \\
\hline & B3LYP & B2PLYP-D2 & B3LYP & B2PLYP-D2 \\
\hline$r(\mathrm{Li}-\mathrm{Li})$ & 2.857 & 2.832 & 2.855 & 2.831 \\
\hline$r(\mathrm{Li}-\mathrm{C})$ & 2.138 & 2.151 & 2.137 & 2.150 \\
\hline$\theta(\mathrm{C}-\mathrm{Li}-\mathrm{Li})$ & 180.0 & 180.0 & 180.0 & 180.0 \\
\hline$\theta(\mathrm{N}-\mathrm{C}-\mathrm{C}-\mathrm{N})$ & 0.2 & 0.2 & 90.0 & 90.0 \\
\hline$\Delta G$ & 0.0 & 0.0 & 1.5 & 1.6 \\
\hline
\end{tabular}

${ }^{a}$ Basis set $6-311++\mathrm{G}(\mathrm{d}, \mathrm{p}) . r$ indicates bond distances in units of $\AA, \theta$ bond or dihedral angles in degrees, and $\Delta G$ Gibbs free energies relative to $\mathbf{2 a}$ in $\mathrm{kcal} / \mathrm{mol}$.

The conformers $\mathbf{2 a}$ and $\mathbf{2 b}$ of IMeLiLiIMe are analogous to $\mathbf{1 a}$ and $\mathbf{1 b}$ of IDipLiLiIDip. The bond lengths and angles of $\mathbf{2 a}$ and $\mathbf{2 b}$ indicate that each lithium( $(0)$ atom is 
$s p$-hybridized, forming a covalent bond with the other lithium( $(0)$ atom and a coordinate covalent bond with a carbenic carbon atom. To further characterize the bonding in $\mathbf{2 a}$ and $\mathbf{2 b}$, we have performed an MO analysis using the method known as the Adaptive Natural Density Partitioning (AdNDP). ${ }^{33}$ The AdNDP-generated localized MOs indicate three pairs of electrons involved in lithium-containing bonds, including a $\mathrm{Li}-\mathrm{Li}$ covalent bond and two $\mathrm{Li}-$ $\mathrm{C}$ coordinate covalent bonds (Figure 3 ). The $\mathrm{Li}-\mathrm{C}$ bonds are of the coordinate nature because the electrons derive entirely from the carbenic carbon atoms in the partitioning process. The full set of AdNDP MOs is given in the Supplementary data (Figures S1 and S2).

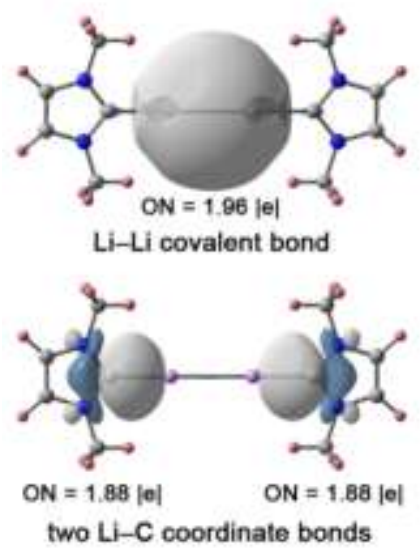

$2 a$

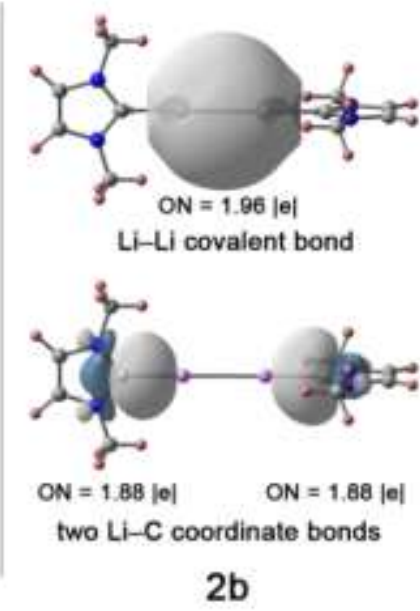

$2 b$

Figure 3. AdNDP-generated localized MOs concerning $\mathrm{Li}-\mathrm{C}$ and $\mathrm{Li}-\mathrm{Li}$ bonds in $\mathbf{2 a}$ and $\mathbf{2} \mathbf{b}$. ON denotes electronic occupation number.

Thermodynamically, the conformers $\mathbf{1 a}$ and $\mathbf{2 a}$, where the two NHC rings are approximately coplanar, are somewhat more stable than the corresponding perpendicular isomers $\mathbf{1 b}$ and $\mathbf{2 b}$. An insight into this difference is to consider two opposing forces-steric repulsion and dispersion attraction - that can operate between the two substituted-NHC ligands. The large separation (by three bonds) of the NHC ligands minimizes steric repulsion, and the nearly coplanar orientation in $\mathbf{1 a} / \mathbf{2 a}$ positions the NHC ligands, particularly the hydrocarbon substituents, somewhat closer to each other than in $\mathbf{1 b} / \mathbf{2} \mathbf{b}$, thereby inducing stronger attractive dispersion forces. This analysis is illustrated in Figure 4 using $\mathbf{2 a}$ and $\mathbf{2 b}$.

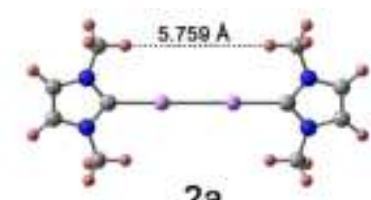

2a

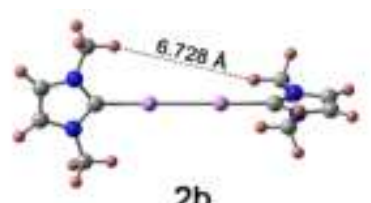

$2 b$

Figure 4. Attractive dispersion interactions between NHC ligands at the closest distances in $\mathbf{2 a}$ and $\mathbf{2 b}$. 
In order to gain insights into the stability of the designed NHCLiLiNHC complexes and the strength of the $\mathrm{Li}-\mathrm{Li}$ bonds thereof, we have selected $\mathbf{2 a}$ as a representative and performed energy analysis on its decomposition. We considered two different reaction routes (eqs 1 and 2) and calculate the associated thermodynamic changes in the gas phase at the B2PLYP-D2/6-311++G(d,p) level. The $\Delta G_{1}$ for the decomposition of $2 \mathbf{a}$ into $\mathrm{Li}_{2}$ and the free NHC ligand has a large positive value (eq 1). This indicates that $\mathbf{2 a}$ would be stable towards

$$
\begin{aligned}
& \operatorname{IMeLiLiIMe}(\mathbf{2 a}) \rightarrow \mathrm{Li}_{2}+2 \mathrm{IMe} \\
& \Delta G_{1}=24.7 \mathrm{kcal} / \mathrm{mol}
\end{aligned}
$$

decomposition into its molecular components. In other words, the reverse reaction, trapping of the $\mathrm{Li}_{2}$ molecule in an NHC complex, would be energetically favorable although it might not the best synthetic approach.

To evaluate the $\mathrm{Li}-\mathrm{Li}$ bond energy of $\mathbf{2 a}$, we calculated the $\Delta E(0 \mathrm{~K})$ for the dissociation of the $\mathrm{Li}-\mathrm{Li}$ bond (eq 2), using the zero-point energy-corrected electronic energies $\left(E_{\mathrm{ZPE}}\right)$. The $\Delta E(0 \mathrm{~K})$ value agrees well with the spectroscopically determined bond energy of $\mathrm{Li}_{2}(22.7-26.4 \mathrm{kcal} / \mathrm{mol}) .{ }^{13-17}$ Also noteworthy is the fact that the lithium( 0$)$ radical complex LiIMe is located as an energy minimum. This offers insight into a potential

$$
\begin{aligned}
& \operatorname{IMeLiLiIMe}(\mathbf{2 a}) \rightarrow 2 \mathrm{LiIMe} \\
& \Delta E(0 \mathrm{~K})=2 E_{\mathrm{ZPE}}(\mathrm{LiIMe})-E_{\mathrm{ZPE}}(\mathbf{2 a})=24.1 \mathrm{kcal} / \mathrm{mol} \\
& \Delta G_{2}=16.2 \mathrm{kcal} / \mathrm{mol}
\end{aligned}
$$

synthetic route; that is, reduction of appropriate $\mathrm{Li}(\mathrm{I})-\mathrm{NHC}$ complexes could produce a Li(0)-NHC radical intermediate, which could subsequently dimerize to form the target lithium(0) complex NHCLiLiNHC. Furthermore, the dimerization, which is the reverse reaction of eq 2, would have a favorable driving force $(-16.2 \mathrm{kcal} / \mathrm{mol})$.

In conclusion, we have demonstrated computationally that NHC-stabilized homoatomic lithium(0) complexes with a $\mathrm{Li}-\mathrm{Li}$ covalent bond should be chemically viable and therefore provide synthetic targets for experimentalists. Such zerovalent dilithium complexes would represent a new class of molecular "allotropes" and could have novel reactivities. The study of such compounds would help advance the field of main-group organometallic chemistry. 


\section{Acknowledgement}

The authors acknowledge support for this work from the University of Colorado Denver. X.W. acknowledges computer time allocation from the Extreme Science and Engineering Discovery Environment (XSEDE), which is supported by National Science Foundation grant number ACI-1053575. C.Y. acknowledges financial support from Shanxi University and the China Scholarship Council. Y.W. acknowledges financial support from Shanxi University and the National Science Foundation of China (Grant No. 21273140). We thank Professor Zhi-Xiang Wang for helpful discussions.

\section{Appendix A. Supplementary data}

Supplementary data related to this article can be found at http:// dx.doi.org/10.1016/j.jorganchem.xxxxxx.

\section{References}

[1] Selected reviews: (a) C. J. Carmalt, Main Group Carbenes. Encyclopedia of Inorganic and Bioinorganic Chemistry [Online]; John Wiley \& Sons, Posted December 15, 2011;

(b) D.J.D. Wilson, J.L. Dutton, Chem.-Eur. J., 19 (2013) 13626-13637;

(c) Y.Z. Wang, G.H. Robinson, Inorg. Chem., 53 (2014) 11815-11832;

(d) H. Braunschweig, R.D. Dewhurst, Organometallics, 33 (2014) 6271-6277.

[2] (a) P.P. Power, Chem. Rev., 99 (1999) 3463-3503;

(b) R.C. Fischer, P.P. Power, Chem. Rev., 110 (2010) 3877-3923.

[3] Y. Wang, B. Quillian, P. Wei, C.S. Wannere, Y. Xie, R.B. King, H.F. Schaefer, P.V. Schleyer, G.H. Robinson, J. Am. Chem. Soc., 129 (2007) 12412-12413.

[4] H. Braunschweig, R.D. Dewhurst, K. Hammond, J. Mies, K. Radacki, A. Vargas, Science, 336 (2012) 1420-1422.

[5] A. Papakondylis, E. Miliordos, A. Mavridis, J. Phys. Chem. A, 108 (2004) 4335-4340.

[6] L.C. Ducati, N. Takagi, G. Frenking, J. Phys. Chem. A, 113 (2009) 11693-11698.

[7] M.P. Mitoraj, A. Michalak, Inorg. Chem., 50 (2011) 2168-2174.

[8] N. Holzmann, A. Stasch, C. Jones, G. Frenking, Chem.-Eur. J., 17 (2011) 1351713525.

[9] S.D. Li, H.J. Zhai, L.S. Wang, J. Am. Chem. Soc., 130 (2008) 2573-2579.

[10] S.A. Couchman, N. Holzmann, G. Frenking, D.J.D. Wilson, J.L. Dutton, Dalton Trans., 42 (2013) 11375-11384.

[11] D.F. Shriver, M.T. Weller, T.L. Overton, J.P. Rourke, F.A. Armstrong, Inorganic Chemistry, 6th ed., Freeman: New York, 2014.

[12] K.P. Huber, G. Herzberg, Molecular Spectra and Molecular Structure. IV. Constants of Diatomic Molecules, Van Nostrand Reinhold Co.: New York, 1979.

[13] R. Velasco, C. Ottinger, R. Zare, J. Chem. Phys., 51 (1969) 5522-5532.

[14] C.H. Wu, J. Chem. Phys., 65 (1976) 2040-2040.

[15] A.R. Miedema, K.A. Gingerich, J. Phys. B: At., Mol. Opt. Phys., 12 (1979) 20812095.

[16] B.M. Smirnov, A.S. Yatsenko, Usp. Fiz. Nauk, 166 (1996) 225-245.

[17] A.J. Ross, P. Crozet, C. Linton, F. Martin, I. Russier, A. Yiannopoulou, J. Mol. Spectrosc., 191 (1998) 28-31.

[18] A. Wacker, H. Pritzkow, W. Siebert, Eur. J. Inorg. Chem., (1998) 843-849.

[19] A.J. Arduengo, M. Tamm, J.C. Calabrese, F. Davidson, W.J. Marshall, Chem. Lett., (1999) 1021-1022. 
[20] R.W. Alder, M.E. Blake, C. Bortolotti, S. Bufali, C.P. Butts, E. Linehan, J.M. Oliva, A.G. Orpen, M.J. Quayle, Chem. Commun., (1999) 1049-1049.

[21] I.V. Shishkov, F. Rominger, P. Hofmann, Organometallics, 28 (2009) 3532-3536.

[22] R. Fränkell, C. Birg, U. Kernbach, T. Habereder, H. Noth, W.P. Fehlhammer, Angew. Chem. Int. Ed. Engl., 40 (2001) 1907-1910.

[23] D.R. Armstrong, S.E. Baillie, V.L. Blair, N.G. Chabloz, J. Diez, J. Garcia-Alvarez, A.R. Kennedy, S.D. Robertson, E. Hevia, Chem. Sci., 4 (2013) 4259-4266.

[24] M.S. Hill, G. Kociok-Kohn, D.J. MacDougall, Inorg. Chem., 50 (2011) 5234-5241.

[25] Geometry optimizations without symmetry constraints were performed in the gas phase at several levels of density functional theory, as specified in the main text. Harmonic frequencies were used to obtain zero-point energy-corrected Gibbs free energies at $298.15 \mathrm{~K}$ and $1 \mathrm{~atm}$. All calculations were performed with Gaussian 09 (ref 26).

[26] M.J. Frisch, et al., in GAUSSIAN 09 Rev. D.01, Gaussian Inc., Wallingford CT, 2013.

[27] (a) C.T. Lee, W.T. Yang, R.G. Parr, Phys. Rev. B, 37 (1988) 785-789;

(b) A.D. Becke, J. Chem. Phys., 98 (1993) 5648-5652.

[28] (a) S. Grimme, J. Chem. Phys., 124 (2006) 034108;

(b) T. Schwabe, S. Grimme, Phys. Chem. Chem. Phys., 9 (2007) 3397-3406.

[29] The covalent radius of lithium $(1.337 \AA$ ) is taken as half of the $\mathrm{Li}-\mathrm{Li}$ bond distance in $\mathrm{Li}_{2}$ (ref. 12). The covalent radius for $s p^{2}$ carbon is $0.73 \AA$ (ref 30).

[30] B. Cordero, V. Gomez, A.E. Platero-Prats, M. Reves, J. Echeverria, E. Cremades, F. Barragan, S. Alvarez, Dalton Trans., (2008) 2832-2838.

[31] M.R. Nadler, C.P. Kempier, Anal. Chem., 31 (1959) 2109-2109.

[32] A. Bondi, J. Phys. Chem., 68 (1964) 441-451.

[33] D.Y. Zubarev, A.I. Boldyrev, Phys. Chem. Chem. Phys., 10 (2008) 5207-5217. 